\section{NASA explores its options for future space programme}

\section{Washington}

A REPORT to be delivered to James Fletcher, administrator of the National Aeronautics and Space Administration (NASA), setting out potential new initiatives for NASA, will undoubtedly add fire to the debate over the direction of the US space programme. Prepared by astronaut Sally Ride, the report will present options ranging from a manned mission to Mars to renewed unmanned exploration of Earth. But the report emphasizes that there are certain steps NASA must take before any new programmes can reasonably be considered.

The Ride report attempts to answer the question of what it means to achieve leadership in space. Reaching the Moon first provided the United States with one type of space leadership, but unmanned exploration and advanced technology development has provided another, perhaps longer lasting, type of leadership.

In addition to the Mars and Earth options, the report examines a possible manned lunar base and unmanned planetary exploration. Along with the Mars and Earth-observing initiatives, these are intended to represent the spectrum of options for NASA. Although no option receives unqualified support, the lunar base and the Earth-observation options seem more reasonable short-term goals.

But the report stresses that virtually any activity NASA may undertake between now and the end of the century will require certain basic improvements. The launch fleet will have to be expanded beyond the shuttle, probably to include a them out of orbit. geostationary platforms. heavy-lift vehicle. There will also be a need for rockets designed to move payloads around once in orbit, and to carry

New technology development is also critical. Apart from special application satellites, much of NASA's hardware is based on technology from the late 1960s and early 1970 s. Space hardware for the 1990 s must include more modern components. Renewed emphasis on life sciences in space is also critical, especially if longer-term missions are undertaken. The report also concludes that a space station of some description will be needed for both manned and unmanned missions.

The emphasis on Earth-observing missions will bring smiles to faces at the National Science Foundation, where Earth sciences have recently been reorganized under the banner of Global Geosciences. Those involved in the International Geosphere-Biosphere Program will see nothing amiss in NASA emphasizing Earth sciences. Planning has already begun at NASA for a fleet of four polar orbiting platforms, two provided by NASA, one by the European Space Agency and one by Japan. These platforms will be serviced by the space station, and used for Earth observations. There are also plans for five

The lunar base may be more controversial, but the Ride report sees it as a critical first step if Mars is to be an ultimate goal. Certainly it will be more expensive than enhanced Earth observation, although not as costly as a trip to Mars would be.

Joseph Palca

\section{Enthusiasm for return to Mars}

\section{Washington}

If the National Aeronautics and Space Administration is uncertain about whether returning to Mars in force should be a goal of the US space programme, such doubts did not exist for participants in this week's "Case for Mars III" conference in Boulder, Colorado. Nor was there doubt about continued Mars exploration during a unique, four-hour video conference between Soviet and US space scientists, engineers and 'explorers' sponsored by the Planetary Society. The video conference, dubbed Spacebridge, took place last Saturday, to coincide with the Mars conference.

About 25 participants from each country discussed issues ranging from the value of international cooperation in planetary exploration to engineering details for future missions. Soviet interest in searching for life on Mars surprised some US participants. Louis Friedman, executive director of the Planetary Society, says part of the video conference was dominated by the life issue. He says the presumption is that by taking samples from further below the surface than those drawn by the US Viking landers warmer, wetter material might be found by Soviet probes. But Friedman adds that there is no clear evidence to suggest that such conditions would in fact exist.

There was no unanimity of opinion on the timing for a manned mission to Mars. Former US astronaut Buzz Aldrin argued that such a mission was achievable before the end of the century, but others felt that was far too optimistic. In mission design discussions, the possibility of cooperating on an engineering model of the martian surface was raised. Cooperation was also proposed as an efficient way of solving navigational problems related to landing on Mars.

\section{British accident practice with radium}

\section{London}

THE British Ministry of Defence admitted last week that it has been using $\alpha$ emitting radioactive materials in nuclear weapons training exercises. The exercises, at undisclosed locations over several years, are designed to simulate accidents involving aircraft or ground vehicles.

Roger Freeman, Parliamentary Under Secretary for the Armed Forces, told a stormy House of Commons last week that liquids containing radium-233 (with a radioactive half-life of about 12 days) have been sprayed around an accident site to make the simulations "as realistic as possible". The ministry says that stringent safety procedures are followed, and that "there is no harmful effect".

The existence of the Nuclear Accident Response Organization, which has conducted the exercises, was revealed by The Independent newspaper. Some members of parliament complained at the use of any kind of radioactivity, but some researchers, accepting the need for "something to

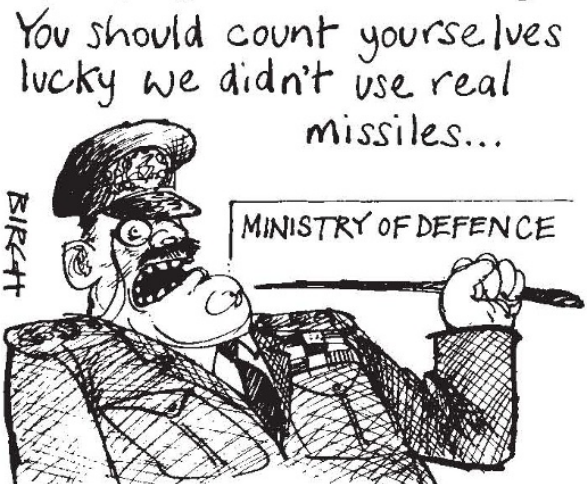

make the geiger counters tick", think it would have been better to avoid $\alpha$ emitters. "A simple $\beta$ - or $\gamma$-emitter would have been better", says Dr Murdoch Baxter of the Scottish University Research Centre.

The ministry says that radium-233 is used "typicaily" but not exclusively on training exercises, when it is mixed with barium sulphate and aluminium oxide. Contaminated soil is removed, and "after three or four months, no trace of radioactivity is left"

The hazards of the practice are disputed. Dr Barrie Lambert, lecturer in radiobiology at St Bartholomew's Hospital in London, says that the use of radium233 is "unjustifiable", given the boneseeking tendency of the material. But the ministry says that the maximum radioactive dose that could be received during an exercise is the equivalent of smoking a single cigarette (radioactive on account of polonium), which is estimated at 50 microsievert.
Kathy Johnston 